\section{Air pollution and health}

SIR - In the light of recent discussions of the effects of air pollution on human health, and of the need for more detailed examination of the effects on those at risk, we write to inform your readers of a joint project by the Italian Research Council (NRC) and the Italian Electric Power Authority, funded by L35,000 million over three years. We believe the epidemiological study that is a major part of this programme has several important and distinctive features.

Two general population samples have been enrolled for longitudinal studies, one in the rural area of the Po River delta, where there is a large thermoelectric plant, and one in the urban and suburban area of Pisa in central Italy, which is polluted mainly by traffic exhausts.

The studies we plan to carry out will allow a measure of both the classical differences of prevalence and incidence rates of respiratory symptoms and diseases and of the cross-sectional and longitudinal differences of lung function after allowing for confounders such as smoking and socioeconomic status.

We also plan to study the distribution of nonspecific bronchial hyperreactivity (methacholine challenge) and the distribution of skin test reactivity and $\operatorname{IgE}$ levels in the two populations. We plan to use haemoglobin adducts to benzene and benzopyrene as biological markers of exposure to vehicle exhausts and nitrous compounds to mark exposure to $\mathrm{NO}_{x}$. We shall score DNA lesions (sister chromatid exchange, micronuclei and so on) in cultures of lymphocytes from the urban subjects and from a subsample of the rural population.

There will also be a series of nested case-control studies of subgroups selected for specific characteristics (for example, non-smokers in the urban areas with the highest and lowest levels of pollution). Serum antibodies to DNA adducts (benzopyrene) will be measured, as will be the presence of DNA adducts in lymphocytes and possibly in alveolar macrophages collected from volunteers from the same subsamples.

The project follows a complex multidisciplinary design. Experts in epidemiology, lung diseases, immunology, allergy, biochemistry, cytogenetics, environmental chemistry and computer science are involved. The sample of the urbansuburban area of Pisa consists of 3,800 people between the ages 8 and 70 selected on the basis of family clusters taken from the most recent census. We have taken account of socioeconomic status, age and sex so as to arrive at a sample representative of the general population.
The study is being carried out with the cooperation and support of the local administration and public health service. The field survey is done by two teams, each consisting of two physicians, one nurse and one technician. The subjects selected for the study have received a detailed letter giving full information about the aims of the study and its protocols, and will be invited by the survey teams to attend one of the public health centres involved in the study for up to 1.5 hours. A questionnaire is used to record respiratory symptoms and to estimate disease and risk factors for obstructive diseases of the respiratory airways. A special section of the questionnaire is devoted to the evaluation of the daily exposure to air pollutants, based on daily activity patterns, in an attempt to estimate the total human exposure.

Data will be collected by automated instrumentation and computers, so that the database will be built and updated 'on-line'. Blood determinations, for example, will be updated periodically. Monitoring of air pollutants $\left(\mathrm{NO}_{2}, \mathrm{SO}_{2}\right.$, total suspended particulates and total hydrocarbons will be carried out. We believe this project is distinctive in using both molecular and biochemical approaches in an epidemiological study.

PAOLO PAOLETT ELIO MARCHES FRANCO VELONA LUIGI DONATO CNR Institute of Clinical Physiology, University of Pisa,

Pisa, Italy

and

ENEL Italian Electric Power Authority, Rome, Italy

\section{Authors by right}

SIR - In proposing an explanation for the tendency of scientists to close ranks during investigations of unbecoming conduct, Louis DeFelice (Nature 353, 104; 1991) has provided an excellent definition of "earned authorship". Authorship is earned by activities that contribute directly and substantially to the intellectual enterprise reported in the paper. These activities would also enable an author to present orally a major part of the work to a critical audience, a familiarity with the material that might be used as a simple criterion of earned authorship in cases of doubt.

Having excluded from the "earned"

Letters submitted for Correspondence should be typed, double-spaced, on one side of the paper only. category authorship gained by other means, the question remains of how to recognize indirect contributions to a paper. The answer must be that suitable credit should be given in the acknowledgements. Some senior scientists burdened with DeFelice's "baggage of success" might well feel aggrieved at the loss of the bogus intellectual kudos of unearned authorship. So be it. In most institutes, these other activities bring their own rewards, rewards that are often denied to the junior researchers who are doing the experiments, analysing the results and writing the papers. If established scientists wish to retain a claim to earned authorship, it is within their powers to set aside sufficient time for direct participation in research. Against the loss of kudos, senior scientists could balance the retention of their scientific integrity and the avoidance of guilt by association when something goes awry.

Junior scientists would probably appreciate some ammunition with which to defend themselves against hitchhiking coauthors. Journal editors should consider adding to their instructions to authors a few lines defining earned authorship and making clear that it is the only form that is acceptable.

JOHN H. R. GEE Department of Biological Sciences, University College of Wales, Aberystwyth

Dyfed SY23 3DA, UK

\section{Nothing new}

SIR - The statement (Nature 354, 177; 1991) that the proposed Korean science tax is "unprecedented" is incorrect. Under Republic Act No. 5448 effective 1 January 1969, the Philippines imposed a special documentary stamp tax where

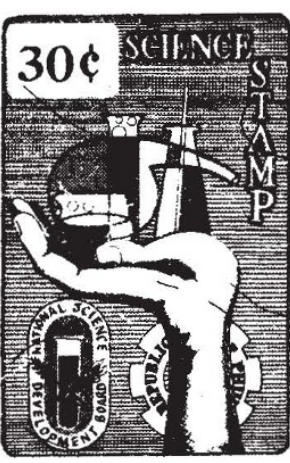
proceeds went to the National Science Development Board. The tax rate was generally 100 per cent of the then current regular documentary tax rate. A series of 15 stamps (example illustrated) ranging in face value from 2 centavos to 100 pesos was issued to prove payment of this tax (for philatelic details, see Am. Revenuer 31, 28-29 \& 51; 1977). When (or whether) the tax and the use of the stamps ceased I do not know.

Psychology Department,

Pace University,

Bedford Road,

Pleasantville, New York 10570, USA 